\title{
Protein intake and the risk of premenstrual syndrome
}

\author{
Serena C Houghton ${ }^{1, *}$, JoAnn E Manson 2,3,4, Brian W Whitcomb 1 , Susan E Hankinson 1,2, \\ Lisa M Troy ${ }^{5}$, Carol Bigelow ${ }^{1}$ and Elizabeth R Bertone-Johnson ${ }^{1}$ \\ 'Department of Biostatistics and Epidemiology, University of Massachusetts, 715 North Pleasant Street, Arnold \\ House 412, Amherst, MA 01003, USA: ${ }^{2}$ Channing Division of Network Medicine, Department of Medicine, \\ Brigham and Women's Hospital and Harvard Medical School, Boston, MA, USA: ${ }^{3}$ Division of Preventive Medicine, \\ Department of Medicine, Brigham and Women's Hospital and Harvard Medical School, Boston, MA, USA: \\ ${ }^{4}$ Department of Epidemiology, Harvard T.H. Chan School of Public Health, Boston, MA, USA: ${ }^{5}$ Department of \\ Nutrition, University of Massachusetts, Amherst, MA, USA
}

Submitted 25 March 2018: Final revision received 12 0ctober 2018: Accepted 10 December 2018: First published online 18 February 2019

\begin{abstract}
Objective: To examine the relationship between protein intake and the risk of incident premenstrual syndrome (PMS).

Design: Nested case-control study. FFQ were completed every 4 years during follow-up. Our main analysis assessed protein intake 2-4 years before PMS diagnosis (for cases) or reference year (for controls). Baseline (1991) protein intake was also assessed.

Setting: Nurses' Health Study II (NHS2), a large prospective cohort study of registered female nurses in the USA.

Participants: Participants were premenopausal women between the ages of 27 and 44 years (mean: 34 years), without diagnosis of PMS at baseline, without a history of cancer, endometriosis, infertility, irregular menstrual cycles or hysterectomy. Incident cases of PMS ( $n$ 1234) were identified by self-reported diagnosis during 14 years of follow-up and validated by questionnaire. Controls ( $n$ 2426) were women who did not report a diagnosis of PMS during follow-up and confirmed experiencing minimal premenstrual symptoms.

Results: In logistic regression models adjusting for smoking, BMI, B-vitamins and other factors, total protein intake was not associated with PMS development. For example, the OR for women with the highest intake of total protein 2-4 years before their reference year (median: $103.6 \mathrm{~g} / \mathrm{d}$ ) $v$. those with the lowest (median: $66.6 \mathrm{~g} / \mathrm{d}$ ) was $0.94(95 \%$ CI $0.70,1 \cdot 27)$. Additionally, intakes of specific protein sources and amino acids were not associated with PMS. Furthermore, results substituting carbohydrates and fats for protein were also null.

Conclusions: Overall, protein consumption was not associated with risk of developing PMS.
\end{abstract}

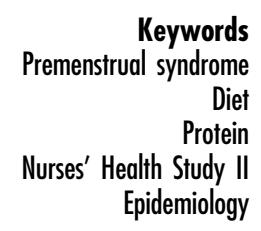

Up to $20 \%$ of reproductive-aged women meet clinical diagnostic criteria for premenstrual syndrome (PMS) ${ }^{(1,2)}$, a cyclical disorder characterized by physical and emotional symptoms occurring during the late luteal phase of the menstrual cycle and abating within a few days following the onset of menses. While the aetiology of PMS is still largely unknown, an interaction between hormonal, neural, genetic, psychosocial and dietary factors likely contributes $^{(3)}$.

We hypothesize that protein intake may be related to PMS through several potential physiological mechanisms, including actions of sex steroid hormones and neurotransmitters, and/or the renin-angiotensin-aldosterone system $^{(4)}$. Protein intake may alter sex hormone levels, as $17 \beta$-oestradiol and progesterone levels are found to decrease with increasing soya protein intake ${ }^{(5)}$. Higher animal protein intake has been associated with higher total and free oestradiol levels and lower sex hormone-binding globulin level, potentially due to the increase in exogenous hormones ${ }^{(6)}$. Additionally, high protein intake and intake of specific amino acids may plausibly lower PMS risk, as tryptophan, glutamate and other amino acids are precursors to neurotransmitters implicated in PMS aetiology ${ }^{(7,8)}$. Lastly, protein intake is reported to increase levels of renin, aldosterone and vasopressin ${ }^{(9)}$, vasoactive hormones of the renin-angiotensin-aldosterone system, 
dysfunction of which has been suggested to contribute to $\operatorname{PMS}^{(10,11)}$.

Women with PMS consumed higher intakes of protein in the premenstrual phase (luteal) compared with the postmenstrual phase (follicular), with no change in intake among controls, in one study examining energy intake over the menstrual cycle ${ }^{(12)}$. The small number of retrospective studies of the relationship between premenstrual symptoms and consumption of protein have reported inconsistent findings ${ }^{(13-15)}$. Additionally, due to the retrospective study design, it is uncertain whether increased protein or amino acid intake precedes the development of PMS or whether intake is affected by symptom occurrence. To our knowledge, no previous study has prospectively evaluated whether protein intake is associated with risk of developing PMS.

Therefore, we evaluated the relationship between protein intake and the development of PMS in the Nurses' Health Study II (NHS2) PMS Sub-Study, a case-control study nested within the prospective NHS2.

\section{Methods}

\section{Study population}

The NHS2 is an ongoing prospective cohort study that has followed 116429 US female nurses, aged 25-42 years in 1989 , since the first mailed questionnaire. Information on health-related behaviours and medical history has been updated biennially and diet quadrennially for over 25 years $^{(16)}$. Response rates have been at least $89 \%$ for all questionnaire cycles.

\section{Classification of premenstrual syndrome cases and controls}

The NHS2 PMS Sub-Study, described previously ${ }^{(16,17)}$, includes a subset of premenopausal women who did not report that they had or ever had PMS on the 1989 or 1991 questionnaire. Over 14 years of follow-up (1993-2007 questionnaires), 4108 participants reported new clinicianmade diagnoses of PMS. For these women we assigned diagnosis year as their reference year. Women who had never reported a diagnosis of PMS by a clinician were randomly assigned a reference year between 1991 and 2005, of whom 3248 were frequency-matched to cases based on age and reference year. Among both groups, women with a history of cancer other than nonmelanoma skin cancer, endometriosis, extremely irregular menstrual cycles, infertility and hysterectomy prior to their reference year were excluded to limit the possibility that PMS-like symptoms were due to another condition. Additionally, because of our interest in diet, those with implausible energy intakes (i.e. those below $2092 \mathrm{~kJ}$ $(500 \mathrm{kcal})$ and above $14644 \mathrm{~kJ}(3500 \mathrm{kcal}))$ were also excluded. Potential cases and controls were then mailed a modified version of the Calendar of Premenstrual Experiences (COPE) questionnaire ${ }^{(17,18)}$ assessing occurrence, timing and impact on several domains of daily functioning of twenty-six premenstrual symptoms in the specified 2-year period before their individual reference year, to confirm case and control status ${ }^{(16)}$. The response rates were $86 \%$ for potential cases and $79 \%$ for potential controls.

PMS cases included women who met case criteria for PMS defined by Mortola et al. ${ }^{(18)}$. Specifically, case criteria included: (i) $\geq 1$ physical and $\geq 1$ affective menstrual symptoms; (ii) overall symptom severity of 'moderate' or 'severe' OR 'moderate' or 'severe' effect of symptoms on at least one life activity or relationship domain; (iii) symptoms begin $\leq 14 \mathrm{~d}$ prior to start of menses; (iv) symptoms end $\leq 4 \mathrm{~d}$ after start of menses; and (v) symptoms not present in the week after menses ended ${ }^{(16)}$. Among self-reported cases who responded, 14\% did not meet the first criterion, $52 \%$ for the second criterion, $6 \%$ for the third criterion, $12 \%$ for the fourth criterion and $17 \%$ did not meet the fifth criterion (percentages not mutually exclusive). Controls included women who had no or minimal symptoms that did not impact daily function domains. Control criteria included: (i) no PMS diagnosis; (ii) either no menstrual symptoms OR an overall symptom severity of 'minimal' or 'mild'; and (iii) either 'no effect' or 'mild' effect of symptoms on the life activity and relationship domains. Among those who had not reported a PMS diagnosis and responded, 6\% did not meet the first criterion, $12 \%$ for the second criterion and $11 \%$ did not meet the third criterion. To minimize the likelihood for misclassification of the outcome, women who did not meet either case or control criteria ( $n$ 2946) were excluded from further analysis. This resulted in 1257 validated PMS cases and 2463 validated controls that met criteria.

\section{Assessment of protein intake and other factors}

Intakes of protein-containing foods were assessed via a semi-quantitative 131-item FFQ beginning in 1991 and subsequently every 4 years thereafter. We assessed the intake of total protein, sources of protein (i.e. animal, vegetable, dairy), the ratio of animal to vegetable protein and the intake of specific amino acids (i.e. tryptophan, tyrosine, glutamate). To calculate each woman's total intake of protein and amino acids, the portion size of a single serving of each food or supplement was multiplied by the reported intake frequency. The total amount of each food consumed was then multiplied by the protein or amino acid nutrient content of the food item, and contributions from all food items were summed. Protein intake was then adjusted for total energy intake using the residual $\operatorname{method}^{(19)}$.

The validity of similar FFQ for measuring total protein intake has been demonstrated previously ${ }^{(19)}$. In an 
analysis of ninety-two women, the energy-adjusted correlation between intake reported by the FFQ and the mean of intake measured with two 1 -week diet records was 0.42 for total protein intake ${ }^{(19)}$.

For each participant, we evaluated protein intake at both baseline (1991) and 2-4 years before her individual reference year (the most recent, but still prospective FFQ), to assess longer-term and recent protein intake, respectively. For analyses, dietary information was available for 3660 NHS2 PMS Sub-Study participants at baseline (cases, $n$ 1234; controls, $n$ 2426) and 3638 women 2-4 years prior to their reference year (cases, $n$ 1222; controls, $n$ 2416).

Information on other factors potentially associated with PMS and diet were collected on the biennial questionnaires, including age, smoking status, weight, pregnancy history and oral contraceptive use. Height and menstrual cycle characteristics were assessed on the 1989 questionnaire. History of depression and antidepressant use were assessed on the menstrual cycle questionnaire. Childhood trauma was assessed in 2001 on a separate questionnaire $^{(20)}$. Lastly, macronutrients and micronutrients including vitamin D, B-vitamins, Ca and other minerals were assessed by FFQ.

\section{Statistical analysis}

Age-adjusted means and SD for continuous variables and frequencies for categorical variables were calculated using generalized linear modelling to compare distributions of demographic, behavioural and lifestyle characteristics between cases and controls.

We used unconditional logistic regression to estimate OR and 95\% CI of PMS for women across quintiles of protein and amino acid intake. Covariates were selected as either being important a priori or producing a $10 \%$ change in estimates. Multivariable logistic regression was conducted to assess the relationship between protein intake and PMS risk, controlling for age, reference year, age at menarche, BMI $\left(\mathrm{kg} / \mathrm{m}^{2}\right.$; weight $/$ height $\left.^{2}\right)$, physical activity, ever use of oral contraceptives, parity (pregnancies lasting $\geq 6$ months), smoking status and quantity (pack-years), ever use of antidepressants, significant childhood trauma, vitamin D from dietary sources and total intake of vitamin $\mathrm{B}_{6}$, thiamin, Fe and $\mathrm{Zn}$.

Additionally, we mutually adjusted vegetable, animal and dairy protein for one another to control for potential confounding by variation in protein source, where potential associations could be due to increases or decreases in the other protein sources. For example, vegetable protein was adjusted for intake of dairy and animal protein. Linear trend across quintiles was assessed using the Mantel extension test for trend, where the median value of each protein category was entered into the regression model as a continuous variable.
We further assessed whether a relationship between protein and amino acid intake and PMS varied by age at the reference year ( $<40 v . \geq 40$ years) and smoking status (past/ never $v$. current) via stratified analyses, as the aetiology of PMS may vary between younger and older premenopausal women, and between smokers and non-smokers. The multiplicative interaction terms were evaluated using likelihood ratio tests, where the interaction terms were calculated as the products of a binary stratification factor and indicators of macronutrient quintile.

To assess the possibility that associations between higher protein intake and risk of PMS could be due to lower intake of fats or carbohydrates, we conducted substitution analyses. For example, we compared associations when protein was substituted for fat by including terms in the model for percentage of energy from protein, percentage of energy from carbohydrates, percentage of energy from alcohol and total energy, excluding percentage of energy from fat. Additional substitution models were also conducted looking at substitutions for carbohydrates and fats.

Analyses were conducted using the statistical software package SAS version 9.3. Two-sided $P$ values $<0.05$ were considered statistically significant.

\section{Results}

Characteristics of cases and controls 2-4 years prior to the reference year are shown in Table 1 . Compared with controls, cases were younger and had a higher mean BMI both at 2-4 years prior to the reference year and age 18 years. Cases were more likely to have used oral contraceptives, smoked, have been diagnosed with depression, used antidepressants and have had significant childhood trauma. Additionally, cases had lower intakes of vitamin D from food sources and higher intakes of B-vitamins at 2-4 years prior to the reference year.

Total protein intake 2-4 years prior to the reference year was not associated with development of PMS (Table 2). Overall, sources of protein were not associated with the development of PMS. While higher intakes of dairy protein were associated with lower risk of PMS in the age-adjusted model, the results were no longer significant after adjustments for vitamin D, B-vitamins and other covariates. Higher vegetable protein intake was non-significantly associated with increased risk of PMS in multivariableadjusted models $\left(P_{\text {trend }}=0 \cdot 08\right.$; OR quintile $5 v$. quintile $2=1.26 ; 95 \%$ CI 0.97, 1.65). Results for vegetable, animal and dairy protein intake were similar for mutually adjusted models. Lastly, intakes of tryptophan, tyrosine and glutamate were not associated with the development of PMS (Table 3).

Analyses evaluating protein and amino acid intake at baseline in 1991 were similar to results presented for the reference year (results not shown). For example, the OR 
Table 1 Age-standardized characteristics of premenstrual syndrome (PMS) cases and controls at 2-4 years prior to the reference year ( $n$ 3638); Nurses' Health Study II PMS Sub-Study, 1991-2005

\begin{tabular}{|c|c|c|c|c|c|}
\hline \multirow[b]{2}{*}{ Characteristic $^{*}$} & \multicolumn{2}{|c|}{ Cases $(n 1222)$} & \multicolumn{2}{|c|}{ Controls (n 2416) } & \multirow[b]{2}{*}{$P$ value $\dagger$} \\
\hline & Mean & SD & Mean & SD & \\
\hline Age (years) & $37 \cdot 2$ & $4 \cdot 3$ & $38 \cdot 6$ & 4.4 & $<0.001$ \\
\hline \multicolumn{6}{|l|}{ BMI $\left(\mathrm{kg} / \mathrm{m}^{2}\right)$} \\
\hline At 2-4 years prior to reference year & $25 \cdot 3$ & $5 \cdot 6$ & $24 \cdot 6$ & $5 \cdot 2$ & $<0.001$ \\
\hline At age 18 years & 21.4 & $3 \cdot 3$ & $21 \cdot 1$ & $3 \cdot 1$ & 0.02 \\
\hline Age at menarche (years) & $12 \cdot 4$ & 1.4 & $12 \cdot 5$ & 1.4 & 0.04 \\
\hline Age at first birth (years) $\ddagger$ & $26 \cdot 4$ & $4 \cdot 2$ & $26 \cdot 5$ & 3.9 & 0.74 \\
\hline Number of full-term pregnancies ( $\geq 6$ months) & 1.9 & $1 \cdot 2$ & 1.9 & $1 \cdot 2$ & 0.40 \\
\hline Physical activity (MET/week) & 28.5 & $95 \cdot 8$ & 24.6 & $65 \cdot 3$ & 0.06 \\
\hline Pack-years of cigarette smoking & 8.6 & $65 \cdot 2$ & $5 \cdot 0$ & $50 \cdot 4$ & 0.07 \\
\hline Alcohol intake $(\mathrm{g} / \mathrm{d})$ & 3.3 & $6 \cdot 0$ & 3.7 & $6 \cdot 8$ & 0.31 \\
\hline Total energy intake $(\mathrm{kJ} / \mathrm{d})$ & 7594 & 2247 & 7640 & 2167 & 0.50 \\
\hline Vitamin D intake from food sources $(\mu \mathrm{g} / \mathrm{d}) \S$ & 5.9 & $2 \cdot 8$ & $6 \cdot 1$ & 3.1 & 0.02 \\
\hline Total vitamin $B_{6}$ intake $(\mathrm{mg} / \mathrm{d}) \S$ & 9.9 & $28 \cdot 7$ & $6 \cdot 8$ & $19 \cdot 1$ & $<0.001$ \\
\hline Total vitamin $B_{12}$ intake $(\mathrm{mg} / \mathrm{d}) \S$ & $11 \cdot 2$ & $18 \cdot 9$ & $10 \cdot 9$ & $19 \cdot 9$ & 0.19 \\
\hline Total thiamin intake $(\mathrm{mg} / \mathrm{d}) \S$ & 4.4 & $10 \cdot 6$ & 3.9 & 9.5 & 0.04 \\
\hline Total riboflavin intake $(\mathrm{mg} / \mathrm{d}) \S$ & 4.9 & $10 \cdot 6$ & $4 \cdot 3$ & $9 \cdot 2$ & 0.02 \\
\hline Total Fe intake $(\mathrm{mg} / \mathrm{d}) \S$ & 23.9 & 23.4 & $24 \cdot 0$ & $22 \cdot 5$ & 0.45 \\
\hline Total $\mathrm{Zn}$ intake $(\mathrm{mg} / \mathrm{d})$ & $16 \cdot 3$ & 10.5 & $16 \cdot 3$ & $12 \cdot 1$ & 0.87 \\
\hline Total $\mathrm{K}$ intake $(\mathrm{mg} / \mathrm{d})$ & 2996 & 542 & 2991 & 548 & 0.22 \\
\hline \multirow[t]{2}{*}{ Total Ca intake $(\mathrm{mg} / \mathrm{d}) \S$} & 1054 & 449 & 1084 & 447 & 0.26 \\
\hline & \multicolumn{2}{|c|}{$\%$} & \multicolumn{2}{|c|}{$\%$} & \\
\hline History of tubal ligation & \multirow{2}{*}{\multicolumn{2}{|c|}{20}} & \multicolumn{2}{|c|}{21} & 0.89 \\
\hline \multicolumn{4}{|l|}{ Oral contraceptive use } & & \\
\hline Ever & \multicolumn{2}{|c|}{86} & \multicolumn{2}{|c|}{79} & $<0.001$ \\
\hline Current & \multicolumn{2}{|c|}{8} & \multicolumn{2}{|c|}{6} & 0.47 \\
\hline Duration $>4$ years & \multicolumn{2}{|c|}{61} & \multicolumn{2}{|c|}{57} & 0.004 \\
\hline \multicolumn{6}{|l|}{ Smoking status } \\
\hline Current & \multicolumn{2}{|c|}{12} & \multicolumn{2}{|c|}{6} & $<0.001$ \\
\hline Past & \multicolumn{2}{|c|}{28} & \multicolumn{2}{|c|}{18} & $<0.001$ \\
\hline Previously diagnosed with depression & \multicolumn{2}{|c|}{18} & \multicolumn{2}{|c|}{8} & $<0.001$ \\
\hline Previously used antidepressant medication & \multicolumn{2}{|c|}{15} & \multicolumn{2}{|c|}{7} & $<0.001$ \\
\hline History of childhood trauma & \multicolumn{2}{|c|}{17} & \multicolumn{2}{|c|}{9} & $<0.001$ \\
\hline
\end{tabular}

MET, metabolic equivalent of task.

${ }^{*}$ All characteristics, except age, are standardized to the age distribution of participants at 2-4 years prior to the reference year. †Calculated using generalized linear model.

łLimited to parous women.

§Energy-adjusted value.

for total protein comparing the highest quintile with the lowest quintile was 0.98 (95\% CI 0.72, 1.34). As BMI may potentially lie within the causal path between protein intake and PMS, the analyses were repeated without BMI and estimates were unchanged. Analyses stratified by smoking status did not suggest effect measure modification and there were no significant interactions found. However, the association between protein and risk of PMS did differ by age at the reference year (Table 4). For total protein, women younger than 40 years at the reference year had non-significant lower risk of PMS development with increasing protein intake. Additionally, interactions were significant for animal protein and vegetable protein sources (both $P_{\text {interaction }}<0 \cdot 01$ ). Among women who were younger than 40 years at the reference year, the OR for animal protein and vegetable protein with PMS comparing the highest quintile of intake with the lowest quintile were 0.58 (95\% CI $0.35,0.96)$ and 1.70 (95\% CI 1.10, 2.62), respectively.
Table 5 presents the results of substitution models, where we assessed the effect of substituting equivalent energy from different macronutrients for others. This looks at the effect of the compensatory changes in other macronutrients while holding total energy intake constant. In age-adjusted models, substitution of protein or fat for carbohydrate energy appeared to increase the risk of developing PMS. Substitution of protein for carbohydrate energy was associated with a $13 \%$ increase in PMS risk (95\% CI 1.01, 1.26). However, after adjustment for micronutrient intake and other covariates, substitution of protein for carbohydrate energy was not associated with PMS (MV2: OR=1.00; $95 \%$ CI $0.85,1 \cdot 17)$. Similarly, substitution of fat for carbohydrate energy was not associated with PMS after adjusting for micronutrients and other covariates (MV2: $\mathrm{OR}=1.00 ; 95 \%$ CI $0.92,1.07)$. Additional substitutions for fat or carbohydrates were not associated with PMS risk. 
Table 2 Age-adjusted and multivariate OR and $95 \% \mathrm{Cl}$ for dietary protein intakes 2-4 years prior to the reference year and risk of premenstrual syndrome (PMS; $n$ 3638); Nurses' Health Study II PMS Sub-Study, 1991-2005

\begin{tabular}{|c|c|c|c|c|c|c|}
\hline & Quintile 1 & Quintile 2 & Quintile 3 & Quintile 4 & Quintile 5 & $P_{\text {trend }}$ \\
\hline \multicolumn{7}{|l|}{ Total protein } \\
\hline Range $(\mathrm{g} / \mathrm{d})$ & $<73.4$ & $73 \cdot 4-80 \cdot 6$ & $80 \cdot 7-87 \cdot 2$ & $87 \cdot 3-95 \cdot 0$ & $>95.0$ & \\
\hline Cases:controls $(n)$ & $236: 419$ & 233:556 & 269:542 & $272: 516$ & $212: 383$ & \\
\hline Age-adjusted & Ref. & 0.73 & 0.88 & 0.93 & 0.98 & 0.49 \\
\hline Model $1^{*}$ & Ref. & 0.73 & 0.91 & 0.90 & 0.94 & 0.83 \\
\hline $95 \% \mathrm{Cl} \dagger$ & - & $0.57,0.94$ & $0 \cdot 70,1 \cdot 18$ & $0.68,1 \cdot 19$ & $0 \cdot 70,1 \cdot 27$ & \\
\hline \multicolumn{7}{|l|}{ Animal protein } \\
\hline Range (g/d) & $<48.6$ & $48 \cdot 6-56 \cdot 9$ & $57 \cdot 0-64 \cdot 0$ & $64 \cdot 1-72 \cdot 8$ & $>72 \cdot 8$ & \\
\hline Cases:controls $(n)$ & $236: 455$ & $245: 521$ & $284: 549$ & $250: 472$ & $207: 419$ & \\
\hline \multicolumn{7}{|l|}{ OR } \\
\hline Age-adjusted & Ref. & 0.90 & 0.99 & 1.02 & 0.94 & 0.99 \\
\hline Model $1^{*}$ & Ref. & 0.86 & 0.96 & 0.94 & 0.82 & 0.33 \\
\hline $95 \% \mathrm{Cl} \dagger$ & - & $0.67,1.11$ & $0.75,1.24$ & $0.71,1.24$ & $0.61,1.11$ & \\
\hline \multicolumn{7}{|l|}{ Vegetable protein } \\
\hline Range (g/d) & $<19 \cdot 4$ & $19 \cdot 4-21 \cdot 8$ & $21 \cdot 9-24 \cdot 3$ & $24.4-27.5$ & $>27.5$ & \\
\hline Cases:controls $(n)$ & $226: 415$ & 244:488 & 243:492 & $237: 512$ & $272: 509$ & \\
\hline \multicolumn{7}{|l|}{ OR } \\
\hline Age-adjusted & Ref. & 0.94 & 0.92 & 0.87 & 1.01 & 0.95 \\
\hline Model $1^{\star}$ & Ref. & 1.01 & 1.03 & 0.99 & 1.26 & 0.08 \\
\hline $95 \% \mathrm{Cl} \dagger$ & - & $0.79,1.29$ & $0.80,1.32$ & $0.76,1.28$ & $0.97,1.65$ & \\
\hline \multicolumn{7}{|l|}{ Dairy protein } \\
\hline Range (g/d) & $<11 \cdot 3$ & $11 \cdot 3-15 \cdot 3$ & $15 \cdot 4-19 \cdot 7$ & $19 \cdot 8-26 \cdot 3$ & $>26 \cdot 3$ & \\
\hline Cases:controls $(n)$ & $201: 379$ & 249:429 & $251: 495$ & $257: 516$ & 264:597 & \\
\hline \multicolumn{7}{|l|}{ OR } \\
\hline Age-adjusted & Ref. & 1.08 & 0.93 & 0.90 & $0 \cdot 81$ & 0.01 \\
\hline Model 1* & Ref. & $1 \cdot 18$ & $1 \cdot 10$ & 0.98 & 0.91 & 0.25 \\
\hline $95 \% \mathrm{Cl} \dagger$ & - & $0.91,1.54$ & $0.83,1.45$ & $0.73,1.31$ & $0.65,1.26$ & \\
\hline \multicolumn{7}{|c|}{ Animal:vegetable protein } \\
\hline Range $(\mathrm{g} / \mathrm{d})$ & $<1.9$ & $1.9-2.4$ & $2.5-2.9$ & $3 \cdot 0-3 \cdot 6$ & $>3.6$ & \\
\hline Cases:controls $(n)$ & 239:525 & $265: 481$ & $257: 519$ & $255: 472$ & $206: 419$ & \\
\hline \multicolumn{7}{|l|}{ OR } \\
\hline Age-adjusted & Ref. & 1.21 & 1.08 & 1.18 & 1.06 & 0.72 \\
\hline Model $1^{*}$ & Ref. & 1.09 & 0.97 & 1.03 & 0.86 & 0.25 \\
\hline $95 \% \mathrm{Cl} \dagger$ & - & $0.86,1.38$ & $0.76,1.23$ & $0.79,1.33$ & $0.65,1.14$ & \\
\hline
\end{tabular}

Ref., reference category; MET, metabolic equivalent of task.

${ }^{*}$ Adjusted for age (continuous), reference year (1991-1992, 1993, 1994-1996, 1997-1998, 1999-2000, 2001-2002, 2003-2004), age at menarche (continuous), BMI ( $\left.\leq 19 \cdot 9,20 \cdot 0-22 \cdot 9,22 \cdot 5-24 \cdot 9,25 \cdot 0-27 \cdot 4,27 \cdot 5-29 \cdot 9, \geq 30 \mathrm{~kg} / \mathrm{m}^{2}\right)$, physical activity $(<3,3-8,9-17,18-26$, $27-41, \geq 42 \mathrm{MET} /$ week), oral contraceptive use (none, 1-23, 24-71, 72-119, $\geq 120$ months), parity (nulliparous, $1-2,3-4$, $\geq 5$ pregnancies $\geq 6$ months), smoking status (never, past $1-14$, past $15-34$, past $\geq 35$, current $1-14$, current $15-34$, current $\geq 35$ cigarettes/d), ever use of antidepressants (never, ever), childhood trauma score $(5,6-10,11-15,16-20,21-25)$, vitamin $D$ from dietary sources (quintile) and quintile of total intake for vitamin $\mathrm{B}_{6}$, thiamin, Fe and $\mathrm{Zn}$ at $2-4$ years prior to the reference year.

†95\% Cl is for multivariable model.

\section{Discussion}

To our knowledge, the present study is one of the first to evaluate prospectively if protein and amino acid intakes are associated with the development of PMS. Overall, we found little evidence that protein intake relates to PMS.

Results from previous studies of protein intake and premenstrual symptoms have been inconsistent. Nagata et al. evaluated the relationship of total protein intake and premenstrual symptoms among Japanese women aged 19-34 years $(n \text { 189 })^{(13)}$. Total protein (mean protein intake $=76.9(\mathrm{SD} 35.3) \mathrm{g} / \mathrm{d})$ was not correlated with change in total menstrual distress scores in the premenstrual phase. Barnard et al. conducted a crossover study among thirty-three women comparing a low-fat vegetarian diet with a normal diet with B-vitamin supplements and found that the low-fat vegetarian diet decreased the duration of premenstrual symptoms ${ }^{(14)}$. Intakes of protein and fat were significantly different between the normal diet (mean protein intake $=59.8(\mathrm{SD} 17.7) \mathrm{g} / \mathrm{d})$ and low-fat vegetarian diet (mean protein intake $=43.5(\mathrm{sD} 11.5) \mathrm{g} / \mathrm{d})$. However, it is unclear whether this is due to the vegetarian diet, lower protein intakes, B-vitamin supplements and/or the low-fat diet. Lastly, Steinberg et al. conducted a clinical trial assessing supplementation of tryptophan $(6 \mathrm{~g})$ in women with premenstrual dysphoric disorder for $17 \mathrm{~d}$, where supplementation with tryptophan ( $n$ 37) was more effective than placebo $(n$ 34) in reducing mood symptom severity among women with premenstrual dysphoric disorder $^{(21)}$. Our study found no association with tryptophan and risk of developing PMS; however, our mean intake of tryptophan was less than $1 \mathrm{~g}$ (mean $=0.98(\mathrm{sD} 0 \cdot 17) \mathrm{g} / \mathrm{d})$.

Substitution of protein for energy from either fat or carbohydrates was not associated with risk of developing PMS after adjusting for potential confounders. This is consistent with our previous findings that fat ${ }^{(22)}$ and carbohydrates ${ }^{(23)}$ 
Table 3 Age-adjusted and multivariate OR and $95 \% \mathrm{Cl}$ for amino acid intakes 2-4 years prior to the reference year and risk of premenstrual syndrome (PMS; $n$ 3638); Nurses' Health Study II PMS Sub-Study, 1991-2005

\begin{tabular}{|c|c|c|c|c|c|c|}
\hline & Quintile 1 & Quintile 2 & Quintile 3 & Quintile 4 & Quintile 5 & $P_{\text {trend }}$ \\
\hline \multicolumn{7}{|l|}{ Tryptophan } \\
\hline Range (g/d) & $<0.8$ & $0.8-0.9$ & $0.9-1.0$ & $1 \cdot 0-1 \cdot 1$ & $>1 \cdot 1$ & \\
\hline $\begin{array}{l}\text { Cases:controls }(n) \\
\text { OR }\end{array}$ & $229: 417$ & $232: 523$ & $284: 580$ & $270: 486$ & $207: 410$ & \\
\hline \multicolumn{6}{|l|}{ OR } & \\
\hline Model $1^{*}$ & Ref. & 0.83 & 1.00 & 1.07 & 0.91 & 0.94 \\
\hline $95 \% \mathrm{Cl} \dagger$ & - & $0.65,1.07$ & $0.77,1.30$ & $0.81,1.41$ & $0.67,1.24$ & \\
\hline \multicolumn{7}{|l|}{ Tyrosine } \\
\hline Range (g/d) & $<2 \cdot 6$ & $2 \cdot 6-2 \cdot 8$ & $2 \cdot 9-3 \cdot 1$ & $3 \cdot 2-3 \cdot 4$ & $>3.4$ & \\
\hline $\begin{array}{l}\text { Cases:controls }(n) \\
\text { OR }\end{array}$ & $226: 407$ & $244: 552$ & $272: 529$ & $259: 491$ & $221: 437$ & \\
\hline Age-adjusted & Ref. & 0.79 & 0.92 & 0.95 & 0.91 & 0.92 \\
\hline Model $1^{*}$ & Ref. & 0.82 & 1.02 & 0.92 & 0.90 & 0.76 \\
\hline $95 \% \mathrm{Cl} \dagger$ & - & $0.64,1.06$ & $0.78,1.33$ & $0.69,1.23$ & $0.66,1.23$ & \\
\hline \multicolumn{7}{|l|}{ Glutamate } \\
\hline Range (g/d) & $<14 \cdot 0$ & $14 \cdot 0-15 \cdot 2$ & $15 \cdot 3-16 \cdot 4$ & $16 \cdot 5-17 \cdot 6$ & $>17 \cdot 6$ & \\
\hline $\begin{array}{l}\text { Cases:controls }(n) \\
\text { OR }\end{array}$ & $217: 379$ & $237: 544$ & $265: 525$ & $276: 526$ & $227: 442$ & \\
\hline Age-adjusted & Ref. & 0.75 & 0.88 & 0.90 & 0.89 & 0.86 \\
\hline Model $1^{*}$ & Ref. & 0.84 & 0.98 & 1.00 & 1.01 & 0.58 \\
\hline $95 \% \mathrm{Cl} \dagger$ & - & $0.65,1.08$ & $0 \cdot 76,1 \cdot 28$ & $0.76,1.32$ & $0.75,1.36$ & \\
\hline
\end{tabular}

Ref., reference category.

${ }^{*}$ Adjusted for age, reference year, age at menarche, BMI, physical activity, oral contraceptive use, parity, smoking status, ever use of antidepressants, childhood trauma, vitamin D from dietary sources and total intake of vitamin $\mathrm{B}_{6}$, thiamin, Fe and $\mathrm{Zn}$ at $2-4$ years prior to the reference year.

$+95 \% \mathrm{Cl}$ is for multivariable model.

Table 4 Multivariate OR and $95 \% \mathrm{Cl}$ for dietary protein intakes $(\mathrm{g} / \mathrm{d}) 2-4$ years prior to the reference year and risk of premenstrual syndrome (PMS; $n$ 3638), stratified by age at the reference year; Nurses' Health Study II PMS Sub-Study, 1991-2005

\begin{tabular}{|c|c|c|c|c|c|c|c|c|c|c|c|}
\hline & \multicolumn{2}{|c|}{ Quintile 1} & \multicolumn{2}{|c|}{ Quintile 2} & \multicolumn{2}{|c|}{ Quintile 3} & \multicolumn{2}{|c|}{ Quintile 4} & \multicolumn{2}{|c|}{ Quintile 5} & \multirow[b]{2}{*}{$P_{\text {interaction }}$} \\
\hline & OR & $95 \% \mathrm{Cl}$ & OR & $95 \% \mathrm{Cl}$ & OR & $95 \% \mathrm{Cl}$ & OR & $95 \% \mathrm{Cl}$ & OR & $95 \% \mathrm{Cl}$ & \\
\hline \multicolumn{12}{|l|}{ Total protein } \\
\hline$<40$ years old & 1.00 & Ref. & 0.71 & $0.48,1.07$ & 0.65 & $0.42,1.02$ & 0.68 & $0.43,1.06$ & 0.80 & $0.48,1.31$ & \multirow[t]{2}{*}{$<0.0001$} \\
\hline$\geq 40$ years old & 1.00 & Ref. & 0.66 & $0.47,0.92$ & 1.05 & $0.75,1.47$ & 1.01 & $0.70,1.45$ & 1.02 & $0.68,1.51$ & \\
\hline \multicolumn{12}{|l|}{ Animal protein } \\
\hline$<40$ years old & 1.00 & Ref. & 0.74 & $0.49,1 \cdot 12$ & 0.73 & $0.48,1.12$ & 0.63 & $0.40,1.00$ & 0.58 & $0.35,0.96$ & \multirow[t]{2}{*}{$<0.0001$} \\
\hline \multicolumn{11}{|l|}{ Vegetable protein } & \\
\hline$<40$ years old & 1.00 & Ref. & 0.84 & $0.56,1.26$ & 1.38 & $0.92,2.06$ & 1.55 & $1 \cdot 01,2 \cdot 38$ & 1.70 & $1 \cdot 10,2 \cdot 62$ & \multirow[t]{3}{*}{$<0.0001$} \\
\hline$\geq 40$ years old & 1.00 & Ref. & 1.04 & $0.75,1.45$ & 0.81 & $0.57,1.14$ & 0.72 & $0.50,1.03$ & 1.06 & $0.74,1.52$ & \\
\hline \multicolumn{11}{|l|}{ Dairy protein } & \\
\hline$<40$ years old & 1.00 & Ref. & $1 \cdot 16$ & $0.74,1.82$ & $1 \cdot 10$ & $0.68,1.79$ & 1.00 & $0.61,1.65$ & 0.74 & $0.42,1.30$ & \multirow[t]{2}{*}{0.0001} \\
\hline$\geq 40$ years old & 1.00 & Ref. & $1 \cdot 12$ & $0.80,1.57$ & 1.02 & $0.72,1.45$ & 0.91 & $0.63,1.33$ & 0.95 & $0.62,1.46$ & \\
\hline
\end{tabular}

Ref., reference category.

${ }^{*}$ Models are adjusted for age, reference year, age at menarche, BMI, physical activity, oral contraceptive use, parity, smoking status, ever use of antidepressants, childhood trauma, vitamin D from dietary sources and total intake of vitamin $\mathrm{B}_{6}$, thiamin, Fe and $\mathrm{Zn}$ at $2-4$ years prior to the reference year.

were not associated with PMS risk. This further suggests that macronutrient intake is not associated with PMS risk after controlling for intake of micronutrients (e.g. $\mathrm{Ca}^{(16)}$, B-vitamins ${ }^{(24)}$ ) and other factors (e.g. smoking ${ }^{(25)}$, BMI $^{(26)}$ ) that are potentially correlated with macronutrient intake and have been significantly associated with PMS risk.

Differences in our results compared with previous study findings could potentially be due to confounding by micronutrients. Nagata et al. did not adjust for micronutrients such as vitamin D or B-vitamins ${ }^{(13)}$. However, when we controlled for several micronutrients, we still found no association. The reduction in premenstrual symptom severity for the crossover study by Barnard et al. may have been due to additional differences other than fat intake and source of protein, including differences in micronutrient intakes ${ }^{(14)}$.

One potential reason why the previous studies found associations with tryptophan whereas we found no associations is study design. The previous studies were treatment trials for premenstrual symptoms, while our study assessed risk of developing PMS. Factors that are associated with treatment of existing PMS may not be similarly 
Table 5 Age-adjusted and multivariate $\mathrm{OR}$ and $95 \% \mathrm{Cl}$ for macronutrient ( $5 \%$ of energy) substitution models $2-4$ years prior to the reference year and risk of premenstrual syndrome (PMS; $n$ 3638); Nurses' Health Study II PMS Sub-Study, 1991-2005

\begin{tabular}{|c|c|c|c|c|c|c|}
\hline \multirow[b]{2}{*}{ Substitution } & \multicolumn{2}{|c|}{ Age-adjusted } & \multicolumn{2}{|c|}{$M V 1^{*}$} & \multicolumn{2}{|c|}{ MV2† } \\
\hline & OR & $95 \% \mathrm{Cl}$ & OR & $95 \% \mathrm{Cl}$ & OR & $95 \% \mathrm{Cl}$ \\
\hline Protein for fat & $1 \cdot 10$ & $0.97,1.25$ & $1 \cdot 12$ & $0.95,1.32$ & 1.01 & $0.84,1.23$ \\
\hline Protein for carbohydrate & 1.13 & $1.01,1.26$ & 1.04 & $0.91,1.19$ & 1.00 & $0.85,1.17$ \\
\hline Fat for carbohydrate & 1.06 & $1.00,1.13$ & 0.98 & $0.92,1.05$ & 1.00 & $0.92,1.07$ \\
\hline Fat for protein & 1.05 & $0.95,1.17$ & 1.06 & $0.94,1.20$ & 1.01 & $0.87,1 \cdot 18$ \\
\hline Carbohydrate for fat & 0.97 & $0.92,1.02$ & 1.05 & $0.99,1.12$ & 1.01 & $0.94,1.09$ \\
\hline Carbohydrate for protein & 0.99 & $0.91,1.07$ & 1.06 & $0.97,1.17$ & 1.02 & $0.90,1.15$ \\
\hline
\end{tabular}

MV, multivariable-adjusted.

${ }^{*} \mathrm{MV} 1$ = age, reference year, age at menarche, BMI, physical activity, oral contraceptive use, parity, smoking status, ever use of antidepressants, childhood trauma, vitamin $\mathrm{D}$ from dietary sources and total intake of vitamin $\mathrm{B}_{6}$, thiamin and Fe.

†MV2 $=M V 1+$ history of depression and total intake of $\mathrm{Ca}$, vitamin $\mathrm{B}_{12}$, riboflavin, folate, $\mathrm{Zn}$ and $\mathrm{K}$.

related to risk of developing PMS. Additionally, the supplementation dose in the treatment trials was substantially higher than the average dietary intake of tryptophan in our study; potential benefits of tryptophan are perhaps only achievable with higher intakes than observable in our study or supplementation. Furthermore, in studies of prevalent PMS observing associations with protein intake, it is unclear whether women may have altered their protein intake in response to symptoms of PMS as a method of managing them, or whether protein or amino acids intake contributes to PMS development.

In stratified analyses, among younger women $(<40$ years old), higher intake of protein from animal sources was inversely associated with PMS risk, whereas higher intake of protein from vegetable sources was positively associated with PMS risk. These findings suggest that risk factors may differ for PMS diagnoses at younger $v$. older ages. However, as these findings were unexpected and the mechanism by which this could occur is unclear, future studies are needed.

Similar to other epidemiological studies that use FFQ to assess diet, protein intakes may be misclassified due to issues in the accuracy of food composition tables to assign a mean protein value for each food and women accurately reporting diet history. As exposure was assessed before the diagnosis of PMS, this misclassification is likely not different between women with PMS and women without PMS, and estimates would be biased towards the null. However, misclassification is minimized through use of a validated FFQ, exclusion of those with implausible energy intakes, adjustment for total energy, and ranked comparisons of high intake $v$. low intake using quintiles. Lastly, previous studies within the NHS2 cohort, using the same FFQ, have detected associations of meat and protein intake with other chronic illnesses ${ }^{(27-29)}$. Additionally, as the aetiology of PMS is unknown, it is unclear which dietary exposure period would be most relevant to the development of PMS. While we assessed both longer-term (baseline) and more recent protein intakes (2-4 years prior to diagnosis), we cannot exclude the possibility of associations with intakes even closer to diagnosis $(<2-4$ years prior) or further from diagnosis (e.g. childhood and adolescence). However, prior studies in this cohort have additionally detected associations with dietary intakes 2-4 years prior to $\mathrm{PMS}^{(16,24,30)}$, indicating that it is a potentially relevant aetiological period. Additionally, with the exposure being assessed prior to diagnosis of PMS, we exclude the potential for recall bias and reverse causation.

Due to the large prospective cohort study design, prospective charting was not feasible; however, misclassification of the outcome is minimized by comparing the two ends of the symptom spectrum and excluding those in the middle who met criteria for neither cases nor controls. Symptom recall is likely to be accurate for those who regularly experience severe symptoms that impair daily functioning and for those who regularly experience few, if any symptoms, and is unlikely to be misclassified between these two groups ${ }^{(16)}$. Second, participants had prospectively reported incident PMS diagnoses by a clinician, which were then confirmed by validated retrospective questionnaire. We previously observed that women meeting our criteria for PMS were comparable to those who also reported prospective charting ${ }^{(17)}$.

\section{Conclusion}

In conclusion, we did not observe evidence that protein or amino acid intake was associated with PMS risk. Furthermore, macronutrient intake overall was not associated with PMS after adjusting for micronutrients. As the present study is the first to examine protein intake and development of PMS, confirmation from additional prospective studies that there does not appear to be an important association is needed. Additionally, future studies should examine micronutrients as potential risk factors for PMS development.

\section{Acknowledgements}

Acknowledgements: The authors thank the participants and staff of the NHS2 for their valuable contributions. 
Financial support: This work was supported by the National Institutes of Health (grant number UM1CA176726), (E.R.B.-J., grant number MH076274); a cy pres distribution from Rexall/Cellasene settlement litigation; and a grant from GlaxoSmithKline Consumer Healthcare. The funders had no role in the design, analysis or writing of this article. Conflict of interest: None. Authorship: J.E.M., S.E.H. and E.R.B.-J. designed the research; S.C.H. and E.R.B.-J. conducted the research; J.E.M. and S.E.H. provided essential materials; S.C.H. and E.R.B.-J. performed the statistical analysis; S.C.H. and E.R.B.-J. wrote the paper; B.W.W., L.M.T. and C.B. interpreted study results, reviewed the manuscript for important intellectual content and contributed knowledge of underlying biological mechanisms; S.C.H., J.E.M. and E.R.B.-J. had primary responsibility for the final content. All authors read and approved the final manuscript. Etbics of buman subject participation: This study was conducted according to the guidelines laid down in the Declaration of Helsinki and all procedures involving human subjects were approved by the Institutional Review Board at Brigham and Women's Hospital in Boston, MA; return of mailed questionnaires was considered to be informed consent.

\section{References}

1. Halbreich U, Borenstein J, Pearlstein T et al. (2003) The prevalence, impairment, impact, and burden of premenstrual dysphoric disorder (PMS/PMDD). Psychoneuroendocrinology 28, Suppl. 3, 1-23.

2. Johnson SR (2006) The epidemiology and social impact of premenstrual symptoms. Clin Obstet Gynecol 30, 367-376.

3. Matsumoto T, Asakura H \& Hayashi T (2013) Biopsychosocial aspects of premenstrual syndrome and premenstrual dysphoric disorder. Gynecol Endocrinol 29, 67-73.

4. Houghton SC \& Bertone-Johnson ER (2015) Macronutrients and premenstrual syndrome. In Advances in Medicine and Biology, vol. 87, pp. 137-156 [LV Berhardt, editor]. Hauppauge, NY: NOVA Science Publishers, Inc.

5. Liu S, Willett WC, Stampfer MJ et al. (2000) A prospective study of dietary glycemic load, carbohydrate intake, and risk of coronary heart disease in US women. Am J Clin Nutr $\mathbf{7 1}$, $1455-1461$

6. Brinkman MT, Baglietto L, Krishnan K et al. (2010) Consumption of animal products, their nutrient components and postmenopausal circulating steroid hormone concentrations. Eur J Clin Nutr 64, 176-183.

7. Backstrom T, Andreen L, Birzniece V et al. (2003) The role of hormones and hormonal treatments in premenstrual syndrome. CNS Drugs 17, 325-342.

8. Association of Reproductive Health Professionals (2008) $A$ Quick Reference Guide for Clinicians: Managing Premenstrual Symptoms. Washington, DC: ARHP.

9. Daniels BS \& Hostetter TH (1990) Effects of dietary protein intake on vasoactive hormones. Am J Physiol 258, 1095-100.

10. Janowsky DS, Berens SC \& Davis JM (1973) Correlations between mood, weight, and electrolytes during the menstrual cycle: a renin-angiotensin-aldosterone hypothesis of premenstrual tension. Psychosom Med 35, 143-154.

11. Rosenfeld R, Livne D, Nevo O et al. (2008) Hormonal and volume dysregulation in women with premenstrual syndrome. Hypertension 51, 1225-1230.

12. Cross GB, Marley J, Miles H et al. (2001) Changes in nutrient intake during the menstrual cycle of overweight women with premenstrual syndrome. Br J Nutr 85, 475-482.

13. Nagata C, Hirokawa K, Shimizu N et al. (2004) Soy, fat and other dietary factors in relation to premenstrual symptoms in Japanese women. BJOG 111, 594-599.

14. Barnard ND, Scialli AR, Hurlock D et al. (2000) Diet and sex-hormone binding globulin, dysmenorrhea, and premenstrual symptoms. Obstet Gynecol 95, 245-250.

15. Menkes DB, Coates DC \& Fawcett JP (1994) Acute tryptophan depletion aggravates premenstrual syndrome. $J$ Affect Disord 32, 37-44.

16. Bertone-Johnson ER, Hankinson SE, Bendich A et al. (2005) Calcium and vitamin D intake and risk of incident premenstrual syndrome. Arch Intern Med 165, 1246-1252.

17. Bertone-Johnson ER, Hankinson SE, Johnson SR et al. (2007) A simple method of assessing premenstrual syndrome in large prospective studies. I Reprod Med 52, 779-786.

18. Mortola JF, Girton L, Beck L et al. (1990) Diagnosis of premenstrual syndrome by a simple, prospective, and reliable instrument: the calendar of premenstrual experiences. Obstet Gynecol 76, 302-307.

19. Willett WC (2012) Nutritional Epidemiology, 3rd ed. New York: Oxford University Press.

20. Bertone-Johnson ER, Whitcomb BW, Hankinson SE et al. (2014) Early life emotional, physical, and sexual abuse and the development of premenstrual syndrome: a longitudinal study. J Womens Health 23, 729-739.

21. Steinberg S, Annable L, Young SN et al. (1999) A placebocontrolled clinical trial of L-tryptophan in premenstrual dysphoria. Biol Psychiatry 45, 313-320.

22. Houghton SC, Manson JE, Whitcomb BW et al. (2017) Intake of dietary fat and fat subtypes and risk of premenstrual syndrome in the Nurses' Health Study II. Br J Nutr 118, 849-857.

23. Houghton SC, Manson JE, Whitcomb BW et al. (2018) Carbohydrate and fiber intake and the risk of premenstrual syndrome. Eur J Clin Nutr 72, 861-870.

24. Chocano-Bedoya PO, Manson JE, Hankinson SE et al. (2011) Dietary B vitamin intake and incident premenstrual syndrome. Am J Clin Nutr 93, 1080-1086.

25. Bertone-Johnson ER, Hankinson SE, Johnson SR et al. (2008) Cigarette smoking and the development of premenstrual syndrome. Am J Epidemiol 168, 938-945.

26. Bertone-Johnson ER, Hankinson SE, Willett WC et al. (2010) Adiposity and the development of premenstrual syndrome. $J$ Womens Health (Larchmt) 19, 1955-1962.

27. Malik VS, Li Y, Tobias DK et al. (2016) Dietary protein intake and risk of type 2 diabetes in US men and women. Am J Epidemiol 183, 715-728.

28. Boutot ME, Purdue-Smithe A, Whitcomb BW et al. (2018) Dietary protein intake and early menopause in the Nurses' Health Study II. Am J Epidemiol 187, 270-277.

29. Farvid MS, Cho E, Chen WY et al. (2014) Dietary protein sources in early adulthood and breast cancer incidence: prospective cohort study. BMJ 348, g3437.

30. Chocano-Bedoya PO, Manson JE, Hankinson SE et al. (2013) Intake of selected minerals and risk of premenstrual syndrome. Am J Epidemiol 177, 1118-1127. 